\title{
Is Epidural Injection of Sodium Chloride Solution a True Placebo or an Active Control Agent? A Systematic Review and Meta-Analysis
}

Laxmaiah Manchikanti, MD¹, Nebojsa Nick Knezevic, MD, PhD², Jaya Sanapati, MD³ Alan D. Kaye, MD, PhD ${ }^{4}$, Mahendra Sanapati, MD', and Joshua A. Hirsch, MD

From: ${ }^{1}$ Pain Management Centers of America, Paducah, $\mathrm{KY}$ and Evansville, IN; ${ }^{2}$ Advocate Illinois Masonic Medical Center and College of Medicine, University of Illinois, Chicago, IL; ${ }^{3} \mathrm{HCA}$ Healthcare/USF Morsani College of Medicine GME Programs, Medical Center of Trinity, Trinity, FL; ${ }^{4}$ LSU School

of Medicine, Shreveport,

LA and New Orleans, LA;

5Massachusetts General Hospital and Harvard Medical School, Boston, MA

Address Correspondence: Laxmaiah Manchikanti, MD Pain Management Centers of

America

67 Lakeview Dr.

Paducah, KY 42001

E-mail:

drlm@thepainmd.com

Disclaimer: There was no external funding in the preparation of this manuscript.

Conflict of interest: Dr. Kaye has been a speaker for Merck. Dr. Hirsch is a consultant for Medtronic and Senior Affiliate Research Fellow at the Neiman Policy Institute.

Manuscript received: o6-15-2019

Revised manuscript received: 11-20-2020

Accepted for publication: 12-02-2020

Free full manuscript www.painphysicianjournal.
Background: Epidural injections have been extensively used since their description in 1901, and steroids since their first utilization in 1952. Multiple randomized controlled trials and systematic reviews have reached discordant conclusions regarding the effectiveness of sodium chloride solution and steroids in managing spinal pain.

True placebo-controlled trials with the injection of an inactive substance to unrelated structures have been nonexistent. Consequently, the discussions continue to escalate, seemingly without proper discourse.

In this review, we sought to assess the true placebo nature of saline and the effectiveness of steroids.

Objectives: This assessment of sodium chloride solution is undertaken to assess if it is a true placebo when injected into the epidural space, is effective alone, and whether steroids are effective when injected with sodium chloride solution rather than local anesthetic in managing spinal pain.

Study Design: A systematic review of randomized controlled trials utilizing sodium chloride solution alone, steroids alone, or sodium chloride solution with steroids in managing spinal pain secondary to disc herniation or spinal stenosis.

Methods: The systematic review was performed utilizing Preferred Reporting Items for Systematic Reviews and Meta-Analyses (PRISMA). Cochrane review criteria and Interventional Pain Management techniques--Quality Appraisal of Reliability and Risk of Bias Assessment (IPM-QRB) was used to assess the methodological quality assessment. Qualitative analysis was performed by utilizing best evidence synthesis principles, and quantitative analysis was performed utilizing meta-analysis with conventional methodology and single-arm meta-analysis.

PubMed, Cochrane Library, US National Guideline Clearinghouse, Google Scholar, and prior systematic reviews and reference lists were utilized in the literature search from 1966 through December 2018. The evidence was summarized utilizing principles of best evidence synthesis on a scale of 1 to 5 .

Outcome measures for the present analysis, 20\% improvement from the baseline pain scores or disability scores was considered clinically significant. Effectiveness was determined short-term if it was less than 6 months, whereas longer than 6 months was considered to be long-term.

Results: Of the 8 trials meeting inclusion criteria, 2 trials utilized fluoroscopic imaging and one study utilized ultrasound. All other studies performed the procedure without fluoroscopy.

With dual-arm meta-analysis, there was no significant difference between epidural sodium chloride solution and epidural steroids with sodium chloride solution. Utilizing single-arm analysis, both epidural saline and epidural steroids with saline were effective in reducing $20 \%$ of pain, however, only reducing disability scores by $10 \%$ to $12 \%$.

Based on the qualitative analysis, epidural saline and epidural steroids with saline showed effect beyond placebo and showed level I, or strong evidence, that neither epidural saline, nor epidural steroids with saline are placebo and that both are effective. 
Limitations: Despite 8 randomized controlled trials, only 2 of them utilized fluoroscopy. Overall evidence is considered less than optimal and further studies elucidating these actions are strongly recommended.

Conclusions: The findings of this systematic review and meta-analysis show that epidurally administered sodium chloride solution and sodium chloride solution with steroids may be effective in managing low back and lower extremity pain. Consequently, the findings of this review provide information that epidurally administered sodium chloride solution is not a true placebo.

Key words: Chronic low back pain, epidural injections, local anesthetic, sodium chloride solution, steroids, placebo effect

Pain Physician 2021: 24:41-59

ow back and neck pain continue to be the most frequently encountered disabling spinal conditions with an annual expenditure of $\$ 134.5$ billion in 2016 increased from $\$ 89.2$ billion in 2013 in the United States $(1,2)$. Opioids and epidural injections are the most commonly utilized nonsurgical modalities in managing chronic spinal pain (3-11). The utilization patterns of epidural injections have shown significant increases over the years, even though a decline with reversal of growth patterns has been noted from 2009 to 2016 (3-9). Epidural injections with local anesthetics have been extensively utilized since 1901 (12-18), whereas steroids were not used until $1952(12,19,20)$.

Multiple systematic reviews and other types of analyses have reached discordant conclusions in reference to the effectiveness of steroids in managing spinal pain $(12,15,18,21-33)$. Discordant conclusions are based on various challenges faced in the performance of systematic reviews of randomized controlled trials, with seeming lack of understanding of placebo control and the differences between active- and placebo-controlled studies, misinterpretation of evidence, and finally, conflicts and confluence of interest $(12,21,26,27,34-39)$. Conflicts and confluence of interest have been reported extensively including conversion of facts in a systematic review $(12,21)$. The major tenet of evidence-based medicine is that clinical decisions should be influenced by all relevant high-quality evidence, as opposed to select studies or analysis. Systematic reviews and meta-analyses are aimed at acquiring all available evidence to address a specific research question and must involve a reproducible and thorough search of the literature with critical assessment of the methodological quality of the studies (39). Further, evidence must be presented as intended by the authors of the individual studies.
Analyses by Pinto et al (26) and Chou et al (21) converted all active controls to placebo controls creating lack of validity to these systematic reviews. Chou et al (21) in a protocol and subsequent manuscripts developed for the Agency for Healthcare Research and Quality (AHRQ) defined "placebo interventions" as epidural, saline, or local anesthetic injections without corticosteroid. This was based on the presumption that therapeutic effects in the epidural space are primarily related to the corticosteroids. Notably, some of the same authors had previously described that epidural steroids were ineffective $(21,26)$.

Since the discovery of steroids in the 1940 s by Phillip Hench (40) as potent anti-inflammatory agents, steroids have been injected for numerous chronic painful conditions (41). Although most steroid injections in clinical practice are combined with local anesthetics, they are also combined with sodium chloride solution in experimental settings and occasionally in clinical settings (41), with the presumption that the addition of steroid can increase the duration of the treatment effect (42-46). Except for inflammatory conditions such as rheumatoid arthritis, there is no evidence that steroid injections are disease-modifying agents $(43,45,46)$. Thus any direct effect of steroids on pain generation or transmission continues to be hypothetical. Although there is some experimental evidence demonstrating suppression of ectopic discharge in neuromas by steroids (47), and although preclinical experiments suggest that steroids may reduce neuropathic pain in some, whereas increasing it in others (44), there is no significant evidence of any direct effect on pain generation or transmission. The rationale for epidural steroids is thus a post hoc argument. Bogduk (45) described that because steroids are anti-inflammatory and because they work for sciatica, 
they have been assumed to work by reducing nerve root inflammation. Additionally, some authors have adduced circumstantial evidence from postmortem studies and operative experience showing that lumbar nerve roots can be inflamed and have argued by inference that this must be the pathology they treat with epidural steroids. However, there are no clinical studies demonstrating how inflammatory radiculopathies are distinguished from noninflammatory radiculopathies prior to administering epidural steroids, as well as the differences in effectiveness based on inflammation (45). The only favorable basis has been that epidural steroids were more effective in patients with increased cerebrospinal fluid protein levels (46), even though this criterion, like other putative criteria of inflammatory radiculopathy, has never been applied prospectively (45). It also has been described that proponents of epidural steroids continue to overlook that most commonly used agent, methylprednisolone, may be effective, based on a reversible, local anesthetic effect (48). Thus extensive mechanisms of long-lasting effects of local anesthetics based on neural blockade altering nociceptive input, the reflex mechanism of afferent fibers, self-sustaining activity of the neurons, and the pattern of central neuronal activities have been proposed (49-58). Additionally, studies also have shown that corticosteroid failed to provide any additional significant benefit in nerve infiltration for lumbar disc herniation (54).

To complicate the understanding of placebo, there is also emerging literature showing that a small volume of local anesthetic or normal saline abolishes a motor response induced by a weak current (59-61). In addition, epidural administration of $5 \%$ dextrose (D5W) has shown a lack of electrophysiologic effect $(62,63)$ but showed long-term postinjection analgesia and clinically significant improvement in pain and disability through 12 months in a significant proportion of patients with repeat epidural injections $(64,65)$. Further, transforaminal hypertonic sodium chloride solution has also shown to increase the duration of the effect of epidural steroid injection compared with steroid with local anesthetic alone without hypertonic sodium chloride solution $(66,67)$.

Thus there is more than a theoretical probability that sodium chloride solution placed into the epidural space is not a true placebo, exerting significant effects on nerve conduction providing pain relief and improvement in functional status with epidural administration (68-74). Conversely, the evidence of efficacy is lacking for epidural steroids without the addition of local anesthetic $(15,25,27-30)$.

To resolve these issues and understand the effect of sodium chloride solution in the epidural space, as well as epidural steroid injection without local anesthetic administered through interlaminar, caudal, or transforaminal approaches in the lumbar spine, but also to avoid inappropriate conversions of local anesthetic solutions as placebos, we have undertaken this systematic review and meta-analysis to assess the effectiveness of sodium chloride alone and steroids with sodium chloride solution or alone.

\section{Methods}

The present systematic review was performed based on the methodological and reporting quality of systematic reviews as described by Preferred Reporting Items for Systematic Reviews and Meta-Analyses (PRISMA) (75).

This review focuses on the effectiveness of epidural sodium chloride solution with or without corticosteroid injections for all types of low back pain.

\section{Eligibility Criteria}

\section{Types of Trials}

Randomized controlled trials.

\section{Types of Patients}

Patients in chosen trials had been suffering with chronic low back pain secondary to disc herniation, discogenic pathology without disc herniation or radiculitis or facet joint arthropathy, spinal stenosis, and postsurgery syndrome.

\section{Types of Interventions}

Caudal, interlaminar, and transforaminal epidural injections in the lumbar spine with saline or steroids or combination.

\section{Types of Outcome Measures}

- The primary outcome parameter was pain relief.

- The secondary outcome measure was functional status improvement.

\section{Data Sources}

All available trials, in all languages, from all countries, providing appropriate management with outcome evaluations were considered for inclusion. Searches were performed from the following sources 
without language restrictions:

1. PubMed from 1966

www.ncbi.nlm.nih.gov/pubmed

2. Cochrane Library

www.thecochranelibrary.com

3. US National Guideline Clearinghouse (NGC) www.guideline.gov/

4. Previous systematic reviews and cross references

5. Clinical Trials www.clinicaltrials.gov/

6. All other sources including nonindexed journals and abstracts.

The search period was from 1966 through December 2018.

\section{Search Strategy}

The search strategy emphasized chronic spinal pain treated with epidural injections.

The search terminology was as follows:

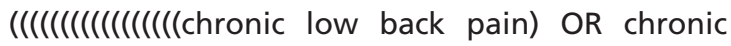
mid back OR upper back pain) OR chronic neck pain) OR disc herniation) $O R$ discogenic pain) $O R$ herniated lumbar discs) $O R$ nerve root compression) $O R$ lumbosciatic pain) OR postlaminectomy) OR lumbar surgery syndrome) $O R$ radicular pain) $O R$ radiculitis) OR sciatica) OR spinal fibrosis) OR spinal stenosis) AND (((()(((()pidural injection) OR epidural steroid) OR epidural perineural injection) $O R$ interlaminar epidural) OR intraarticular corticosteroid) OR nerve root blocks) OR periradicular infiltration) OR transforaminal injection) OR corticosteroid) OR methylprednisolone $O R$ lidocaine) OR bupivacaine))) AND ((meta-analysis [pt] OR randomized controlled trial [pt] OR controlled clinical trial [pt] OR randomized controlled trials [mh] OR random allocation $[\mathrm{mh}] \mathrm{OR}$ double-blind method [mh] OR single-blind method [mh] OR clinical trial [pt] OR clinical trials [mh] OR ("clinical trial" [tw]) OR ((singl* [tw] OR doubl* [tw] OR trebl* [tw] OR tripl* [tw]) AND (mask* [tw] OR blind* [tw])) OR (placebos [mh] OR placebo* [tw] OR random* [tw] OR research design [mh:noexp]).

\section{Data Collection and Analyses}

The review focused only on randomized trials. Only epidural injections with saline with or without steroids were evaluated. All of the studies providing appropriate management and with outcome evaluations and statistical evaluations were reviewed. Reports without appropriate diagnosis, nonsystematic reviews, book chapters, and case reports were excluded.

\section{Data Items}

The population of interest was patients suffering with chronic spinal pain. Patients with acute trauma, fractures, malignancies, and inflammatory diseases were excluded.

\section{Data Collection Process}

Two review authors independently, in an unblinded, standardized manner, developed the search criteria, searched for relevant literature, selected the manuscripts, and extracted the data from the included studies. Disagreements were resolved by discussion between the 2 reviewers; if no consensus could be reached, a third author was called in to break the impasse. If there was a conflict of interest with a reviewed manuscript (concerning authorship), or if the reviewer was also one of the authors or had any type of conflict, the involved reviewer did not review the manuscript for methodological quality assessment.

\section{Data Syntheses and Analyses}

Data syntheses and analyses were performed with assessment of risk of bias or quality of individual studies, outcomes assessment, qualitative and quantitative analyses.

\section{Risk of Bias of Individual Studies}

The quality of each individual article used in this analysis was assessed by Cochrane review (76) criteria and Interventional Pain Management techniques-Quality Appraisal of Reliability and Risk of Bias Assessment (IPM-QRB) for randomized trials (77).

Methodological quality assessment was performed by 2 authors. The assessment was carried out independently in an unblinded, standardized manner to assess the methodological quality and internal validity of all the studies considered for inclusion. Reviewers performed their methodological quality assessment so as to prevent any discrepancies. If discrepancies occurred, a third reviewer performed an assessment, and a consensus was reached. Issues beyond that were discussed by all reviewers and then resolved.

\section{Outcome of the Studies}

For the present analysis, either $20 \%$ improvement from the baseline pain scores or functionality scores was considered clinically significant.

\section{Analysis of Evidence}

The analysis of the evidence was performed based 
on the best evidence synthesis, modified and collated from multiple available criteria, including Cochrane review criteria and US Preventive Task Force (USPSTF) criteria as illustrated in Table 1 (78). The analysis was conducted using 5 levels of evidence ranging from strong to opinion- or consensus-based. The results of best evidence as per grading were utilized.

At least 2 of the review authors independently, in an unblinded, standardized manner, analyzed the evidence. Any disagreements between reviewers were resolved by a third author and consensus. If there were any conflicts of interest (e.g., authorship), those reviewers were recused from assessment and analysis.

\section{Meta-Analysis}

For this meta-analysis, software Review Manager (Rev Man 5.3) was used (The Nordic Cochrane Centre, The Cochrane Collaboration, Copenhagen, Denmark, 2008). For pain and functionality improvement data, the studies were reported as the standardized mean differences (SMD) with $95 \%$ confidence intervals (CI). Data were plotted using forest plots to evaluate treatment effects using random-effects model. Heterogeneity was interpreted through $I^{2}$ statistics.

We also performed single-arm meta-analyses to assess net changes in the same outcome variables $(79,80)$. For this meta-analysis, Comprehensive Meta-Analysis version 3.0 software was used (Biostat Inc., Englewood, $\mathrm{NJ}$ ). For pain and functionality improvement data, the studies were reported as the mean differences with $95 \% \mathrm{Cl}$. Data were plotted using forest plots to evaluate treatment effects. Heterogeneity was interpreted through $I^{2}$ statistics.

\section{RESULTS}

\section{Study Selection}

Figure 1 shows a flow diagram of the study selection as recommended by PRISMA (75).

Following the search criteria, with identification of numerous manuscripts and consideration of inclusion, 13 manuscripts $(68-74,81-86)$ were identified. Of these, 8 manuscripts $(68-71,73,74,82,83)$ met inclusion criteria, with 2 manuscripts utilizing caudal epidural $(71,74), 4$ manuscripts with interlaminar epidural $(68,73,82,83)$, and 2 manuscripts with transforaminal epidural $(69,70)$. One study of transforaminal epidural without fluoroscopy was excluded (86). A trial by Cohen et al (72) was excluded because all patients received bupivacaine prior to administration of sodium chloride solution. Two other studies by Cohen et al $(84,85)$ were excluded as gabapentin was the subject of the study. A study by Revel et al (81) describing forceful injection was excluded.

\section{Study Characteristics}

A description of the various studies included is shown in Table 2.

Of the 8 trials meeting inclusion criteria (68$71,73,74,82,83), 2$ trials utilized fluoroscopic imaging $(69,70)$ and one study utilized ultrasound $(71)$. All other studies performed the procedures without fluoroscopy. Of these, caudal epidural saline alone was injected in 2 trials $(71,74)$, with interlaminar approach in 3 trials $(68,73,83)$, and with transforaminal approach in 2 trials $(69,70)$. In reference to steroids, epidural saline with steroids was utilized in 3 trials with caudal $(71,74)$ and in 2 trials with interlaminar approach $(68,73,82)$.

Table 1. Qualitative modified approach to grading of evidence.

\begin{tabular}{|l|l|l||}
\hline Level I & Strong & Evidence obtained from multiple relevant high-quality randomized controlled trials \\
\hline Level II & Moderate & $\begin{array}{l}\text { Evidence obtained from at least one relevant high-quality randomized controlled trial or multiple relevant } \\
\text { moderate- or low-quality randomized controlled trials }\end{array}$ \\
\hline Level IV & Fair & $\begin{array}{l}\text { Evidence obtained from at least one relevant moderate- or low-quality randomized controlled trial with } \\
\text { multiple relevant observational studies } \\
\text { or } \\
\text { Evidence obtained from at least one relevant high-quality nonrandomized trial or observational study with } \\
\text { multiple moderate- or low-quality observational studies }\end{array}$ \\
\hline Level V & Consensus based & Evidence obtained from multiple moderate- or low-quality relevant observational studies \\
\hline
\end{tabular}

Adapted from Manchikanti L, Falco FJE, Benyamin RM, Kaye AD, Boswell MV, Hirsch JA. A modified approach to grading of evidence. Pain Physician 2014; 17:E319-E325 (78). 


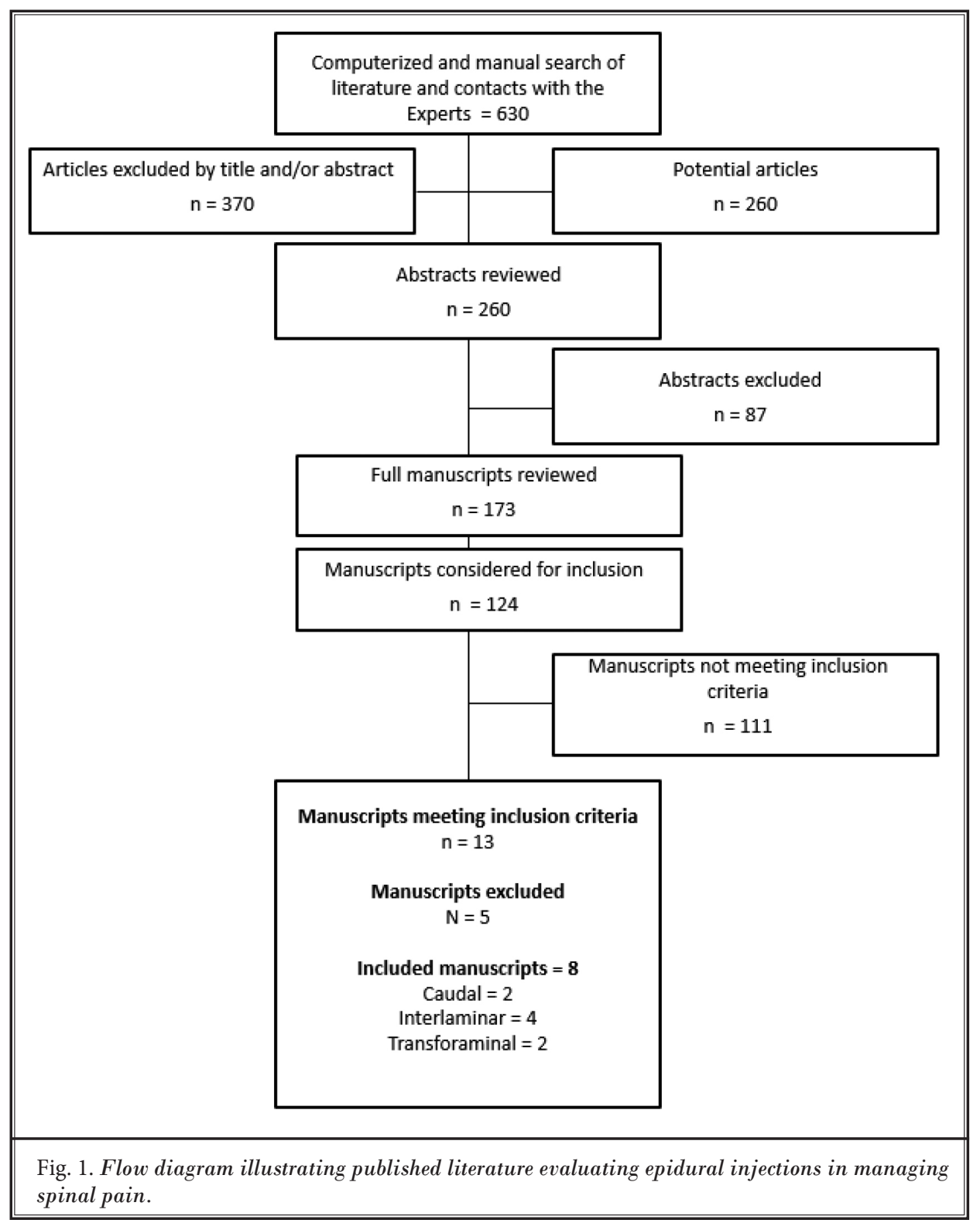

ered to be of moderate quality with a score of 16 to $31(68,71,73,74,82,83)$.

\section{Results Based on Injected Solution(s)}

As shown in Table 5, results of individual studies showed that epidural sodium chloride solution was administered in 5 of 9 studies $(68-71,83)$. Overall, 341 patients were studied in the epidural saline group, whereas 254 patients were studied with epidural saline with steroids.

Table 6 shows results of effectiveness of epidural injections.

\section{Qualitative Analysis}

Among the 5 studies as shown in Tables 2 and 5, which provided appropriate data with the proportion of patients with significant improvement either with pain relief or functional status improvement $(68,69,73,74,83)$, a total of 221 patients were included. Forty percent of them, or 89 patients, showed improvement. In contrast, in patients receiving sodium chloride

\section{Methodological Quality Assessment}

A methodological quality assessment of the randomized controlled trials meeting inclusion criteria was carried out utilizing Cochrane review (76) criteria and IPM-QRB (77) criteria as shown in Tables 3 and 4.

Methodological quality assessment showed 6 of the 8 trials as high quality (score of 9-13) as shown in Table $3(68-70,73,74,82)$, with 2 trials showing moderate quality with a score of 5 to $8(71,83)$ based on Cochrane Review criteria. In contrast, based on IPM-QRB criteria (Table 4), 2 trials were of high quality with a score above $32(69,70)$, whereas the remaining trials were consid- with steroids, there were 4 studies with appropriate data available $(68,73,74,82)$, which included a total of 218 patients with $52 \%$, or 113 patients, showing appropriate improvement in parameters of pain or functional status.

\section{Quantitative Analysis}

Both dual-arm and single-arm meta-analysis was performed. In the performance of meta-analysis, the following issues were noted applicable to both dualarm and single-arm analysis: 
Is Epidural Sodium Chloride a True Placebo?

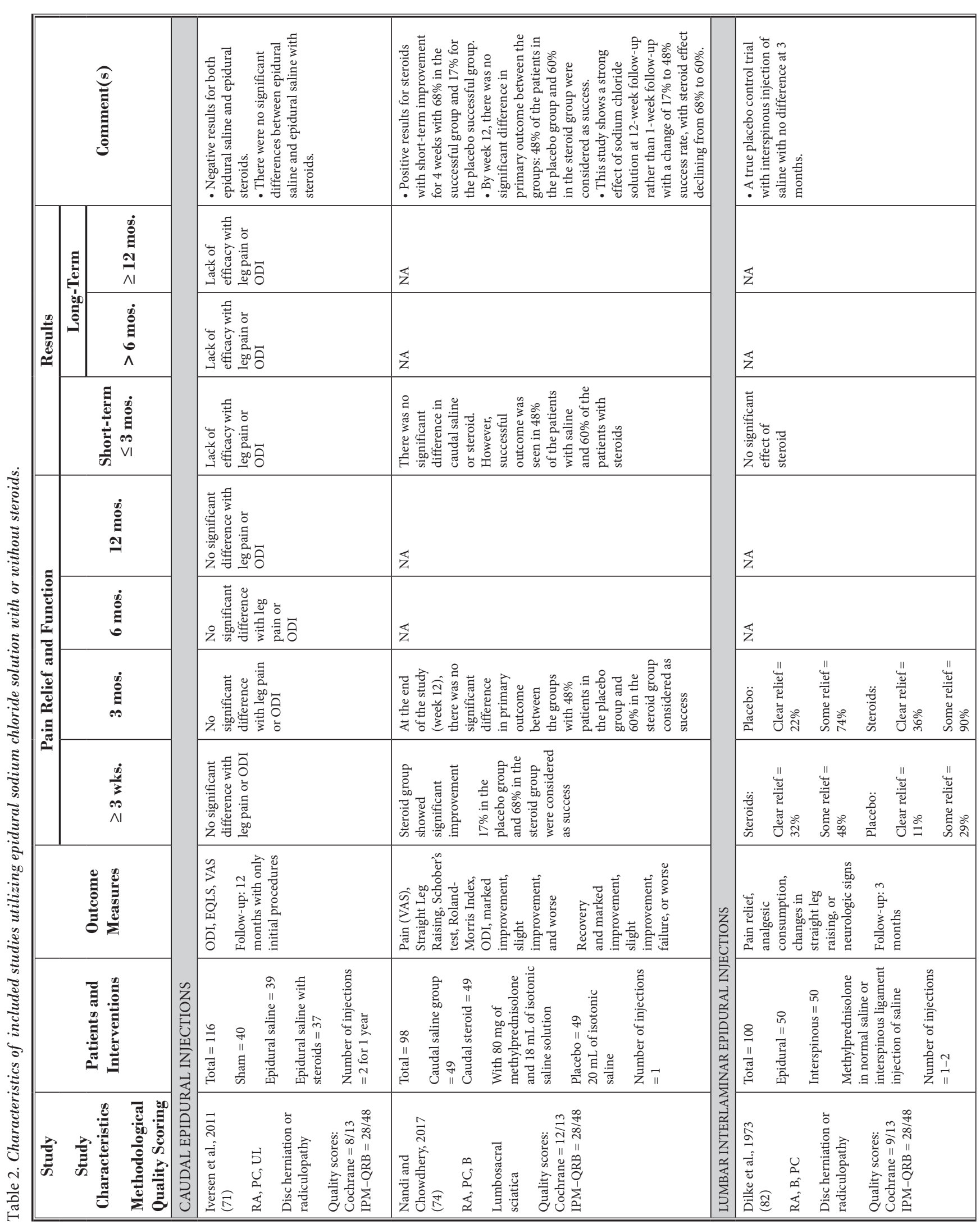


Pain Physician: January/February 2021 24:41-59

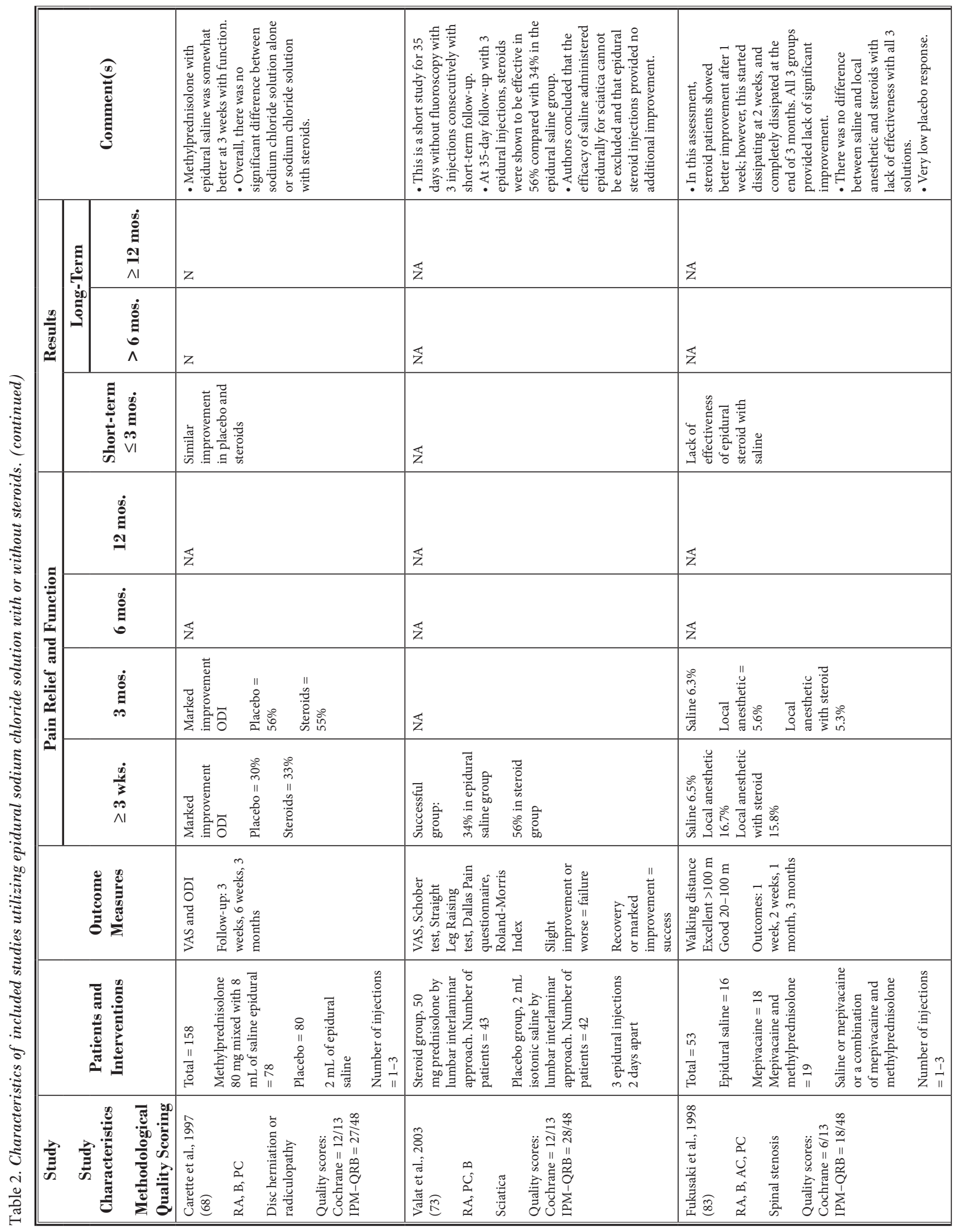




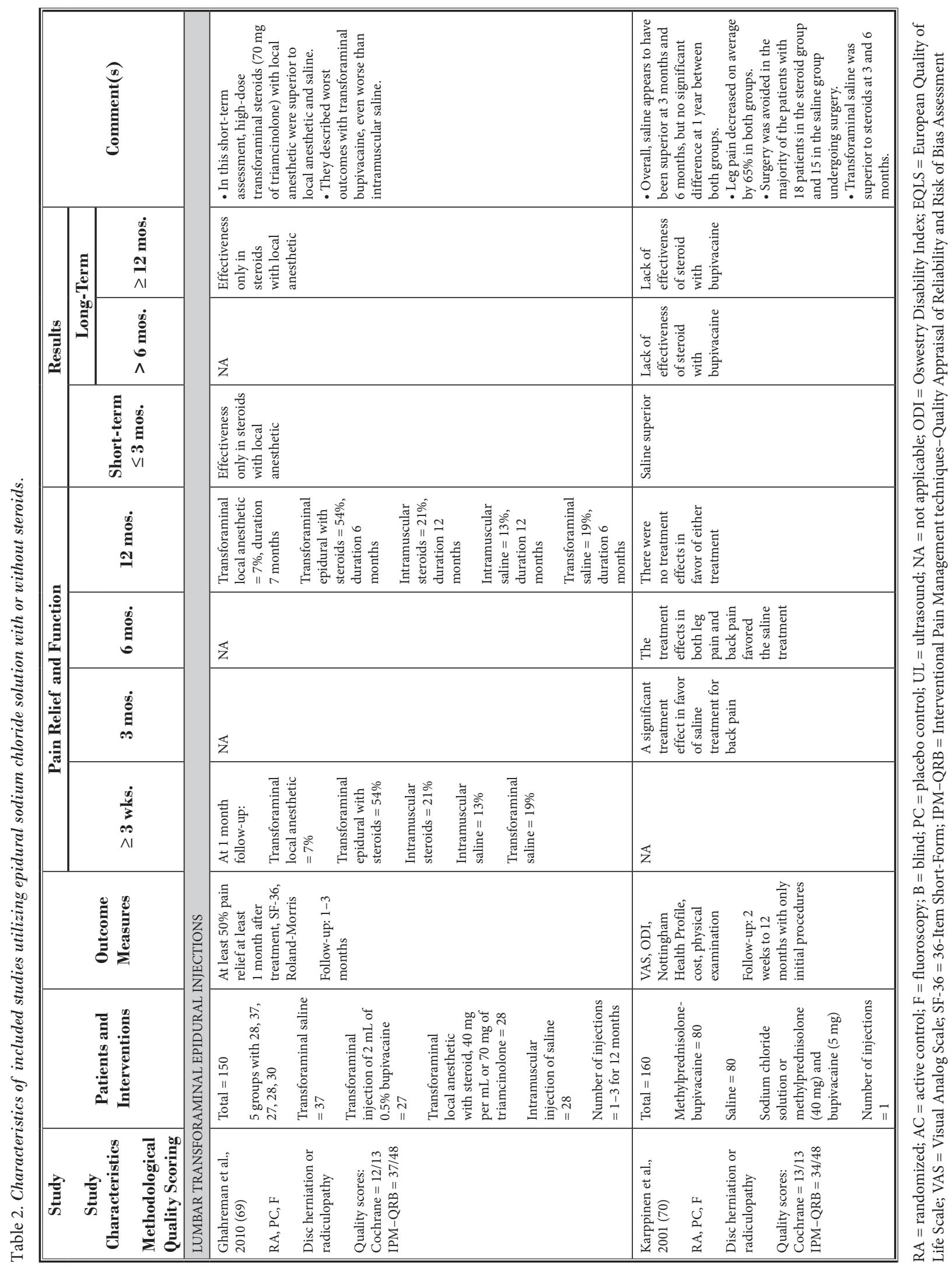


Pain Physician: January/February 2021 24:41-59

Table 3. Methodological quality assessment of randomized trials utilizing Cochrane review criteria.

\begin{tabular}{|c|c|c|c|c|c|c|c|c|}
\hline & $\begin{array}{c}\text { Iversen et al } \\
2011 \text { (71) }\end{array}$ & $\begin{array}{l}\text { Dilke et al } \\
1973(82)\end{array}$ & $\begin{array}{c}\text { Carette et } \\
\text { al } 1997 \\
(68) \\
\end{array}$ & $\begin{array}{c}\text { Fukusaki } \\
\text { et al } 1998 \\
(83) \\
\end{array}$ & $\begin{array}{c}\text { Ghahreman } \\
\text { et al } 2010 \\
(69) \\
\end{array}$ & $\begin{array}{c}\text { Karppinen } \\
\text { et al 2001 } \\
(70) \\
\end{array}$ & $\begin{array}{l}\text { Valat et al } \\
2003(73)\end{array}$ & $\begin{array}{c}\text { Nandi and } \\
\text { Chowdhery } \\
2017 \text { (74) } \\
\end{array}$ \\
\hline $\begin{array}{l}\text { Randomization } \\
\text { adequate }\end{array}$ & $\mathrm{Y}$ & $\mathrm{N}$ & $\mathrm{Y}$ & $\mathrm{N}$ & $\mathrm{Y}$ & $\mathrm{Y}$ & $\mathrm{Y}$ & $\mathrm{Y}$ \\
\hline $\begin{array}{l}\text { Concealed treatment } \\
\text { allocation }\end{array}$ & $\mathrm{Y}$ & $\mathrm{N}$ & $\mathrm{Y}$ & $\mathrm{N}$ & $\mathrm{Y}$ & $\mathrm{Y}$ & $\mathrm{Y}$ & $\mathrm{Y}$ \\
\hline Patient blinded & $\mathrm{Y}$ & $\mathrm{Y}$ & $\mathrm{Y}$ & $\mathrm{N}$ & $\mathrm{Y}$ & $\mathrm{Y}$ & $\mathrm{Y}$ & $\mathrm{Y}$ \\
\hline $\begin{array}{l}\text { Care provider } \\
\text { blinded }\end{array}$ & $\mathrm{N}$ & $\mathrm{N}$ & $\mathrm{N}$ & $\mathrm{N}$ & $\mathrm{Y}$ & $\mathrm{Y}$ & $\mathrm{N}$ & $\mathrm{N}$ \\
\hline $\begin{array}{l}\text { Outcome assessor } \\
\text { blinded }\end{array}$ & $\mathrm{U}$ & $\mathrm{Y}$ & $\mathrm{Y}$ & $\mathrm{U}$ & $\mathrm{Y}$ & $\mathrm{Y}$ & $\mathrm{Y}$ & $\mathrm{Y}$ \\
\hline $\begin{array}{l}\text { Drop-out rate } \\
\text { described }\end{array}$ & $\mathrm{Y}$ & $\mathrm{Y}$ & $\mathrm{Y}$ & $\mathrm{N}$ & $\mathrm{Y}$ & $\mathrm{Y}$ & $\mathrm{Y}$ & $\mathrm{Y}$ \\
\hline $\begin{array}{l}\text { All randomized } \\
\text { participants analyzed } \\
\text { in the group }\end{array}$ & $\mathrm{N}$ & $\mathrm{Y}$ & $\mathrm{Y}$ & $\mathrm{Y}$ & $\mathrm{Y}$ & $\mathrm{Y}$ & $\mathrm{Y}$ & $\mathrm{Y}$ \\
\hline $\begin{array}{l}\text { Reports of the study } \\
\text { free of suggestion of } \\
\text { selective outcome } \\
\text { reporting }\end{array}$ & $\mathrm{Y}$ & $\mathrm{Y}$ & $\mathrm{Y}$ & $\mathrm{Y}$ & $\mathrm{Y}$ & $\mathrm{Y}$ & $\mathrm{Y}$ & $\mathrm{Y}$ \\
\hline $\begin{array}{l}\text { Groups similar at } \\
\text { baseline regarding } \\
\text { most important } \\
\text { prognostic indicators }\end{array}$ & $\mathrm{N}$ & $\mathrm{N}$ & $\mathrm{Y}$ & $\mathrm{Y}$ & $\mathrm{N}$ & $\mathrm{Y}$ & $\mathrm{Y}$ & $\mathrm{Y}$ \\
\hline $\begin{array}{l}\text { Cointerventions } \\
\text { avoided or similar }\end{array}$ & $\mathrm{Y}$ & $\mathrm{Y}$ & $\mathrm{Y}$ & $\mathrm{N}$ & $\mathrm{Y}$ & $\mathrm{Y}$ & $\mathrm{Y}$ & $\mathrm{Y}$ \\
\hline $\begin{array}{l}\text { Compliance } \\
\text { acceptable in all } \\
\text { groups }\end{array}$ & $\mathrm{N}$ & $\mathrm{Y}$ & $\mathrm{Y}$ & $\mathrm{Y}$ & $\mathrm{Y}$ & $\mathrm{Y}$ & $\mathrm{Y}$ & $\mathrm{Y}$ \\
\hline $\begin{array}{l}\text { Time of outcome } \\
\text { assessment in all } \\
\text { groups similar }\end{array}$ & $\mathrm{Y}$ & $\mathrm{Y}$ & $\mathrm{Y}$ & $\mathrm{Y}$ & $\mathrm{Y}$ & $\mathrm{Y}$ & $\mathrm{Y}$ & $\mathrm{Y}$ \\
\hline $\begin{array}{l}\text { Are other sources of } \\
\text { potential bias likely }\end{array}$ & $\mathrm{Y}$ & $\mathrm{Y}$ & $\mathrm{Y}$ & $\mathrm{Y}$ & $\mathrm{Y}$ & $\mathrm{Y}$ & $\mathrm{Y}$ & $\mathrm{Y}$ \\
\hline Score & $8 / 13$ & $9 / 13$ & $12 / 13$ & $6 / 13$ & $12 / 13$ & $13 / 13$ & $12 / 13$ & $12 / 13$ \\
\hline
\end{tabular}

$\mathrm{Y}=$ Yes; $\mathrm{N}=\mathrm{No} ; \mathrm{U}=$ Unclear

Source: Furlan AD, Malmivaara A, Chou R, Maher CG, Deyo RA, Schoene M, Bronfort G, van Tulder MW; Editorial Board of the Cochrane Back, Neck Group. 2015 Updated Method Guideline for Systematic Reviews in the Cochrane Back and Neck Group. Spine (Phila Pa 1976) 2015; 40:1660-1673 (76).

In the study by Dilke et al (82) we could not extract any data because there were no scales for pain or functionality. Fukusaki et al (83) just measured functionality with walking distance and because it was the only study that used this, subsequently, we could not use it for meta-analysis. Ghahreman et al (69) used median and interquartile range; the pain level was measured for the leg, and not the back. Consequently, we could not use it because it was the only study using leg pain. Karp- pinen et al (70) did not provide crude change of each group, only the difference between groups, therefore we could not identify the individual change with these data.

\section{Dual-Arm Meta-Analysis}

Figure 2 shows change in the pain level using Visual Analog Scale (VAS) from baseline at 3 months (Fig. 2A) and functional level (Fig. 2B). There were 3 studies with 
Is Epidural Sodium Chloride a True Placebo?

Table 4. Methodological quality assessment of randomized trials utilizing IPM-QRB.

\begin{tabular}{|c|c|c|c|c|c|c|c|c|c|}
\hline & & $\begin{array}{c}\text { Iversen et } \\
\text { al } 2011 \\
(71)\end{array}$ & $\begin{array}{c}\text { Dilke et } \\
\text { al } 1973 \\
(\mathbf{8 2})\end{array}$ & $\begin{array}{c}\text { Carette et } \\
\text { al } 1997 \\
(68)\end{array}$ & $\begin{array}{c}\text { Fukusaki } \\
\text { et al } 1998 \\
(83)\end{array}$ & $\begin{array}{c}\text { Ghahreman } \\
\text { et al } 2010 \\
(69)\end{array}$ & $\begin{array}{c}\text { Karppinen } \\
\text { et al 2001 } \\
(70)\end{array}$ & $\begin{array}{c}\text { Valat et } \\
\text { al } 2003 \\
(73)\end{array}$ & $\begin{array}{c}\text { Nandi and } \\
\text { Chowdhery } \\
2017(74)\end{array}$ \\
\hline I. & \multicolumn{9}{|c|}{ TRIAL DESIGN AND GUIDANCE REPORTING } \\
\hline 1. & CONSORT or SPIRIT & 2 & 0 & 1 & 0 & 3 & 2 & 1 & 1 \\
\hline II. & \multicolumn{9}{|l|}{ DESIGN FACTORS } \\
\hline 2. & Type and Design of Trial & 2 & 3 & 2 & 2 & 2 & 2 & 2 & 2 \\
\hline 3. & Setting/Physician & 1 & 2 & 2 & 1 & 2 & 1 & 1 & 1 \\
\hline 4. & Imaging & 1 & 0 & 0 & 0 & 3 & 3 & 0 & 0 \\
\hline 5. & Sample Size & 2 & 3 & 3 & 0 & 2 & 3 & 2 & 2 \\
\hline 6. & Statistical Methodology & 1 & 1 & 1 & 1 & 1 & 1 & 1 & 1 \\
\hline III. & \multicolumn{9}{|l|}{ PATIENT FACTORS } \\
\hline 7. & $\begin{array}{l}\text { Inclusiveness of } \\
\text { Population }\end{array}$ & 2 & 2 & 2 & 2 & 2 & 2 & 2 & 2 \\
\hline 8. & Duration of Pain & 1 & 0 & 0 & 1 & 1 & 0 & 0 & 0 \\
\hline 9. & Previous Treatments & 0 & 0 & 0 & 0 & 0 & 0 & 0 & 0 \\
\hline 10. & $\begin{array}{l}\text { Duration of Follow- } \\
\text { Up with Appropriate } \\
\text { Interventions } \\
\end{array}$ & 1 & 1 & 0 & 1 & 0 & 1 & 0 & 0 \\
\hline IV. & \multicolumn{9}{|l|}{ OUTCOMES } \\
\hline 11. & $\begin{array}{l}\text { Outcomes Assessment } \\
\text { Criteria for Significant } \\
\text { Improvement }\end{array}$ & 0 & 2 & 0 & 1 & 4 & 2 & 2 & 2 \\
\hline 12. & $\begin{array}{l}\text { Analysis of all } \\
\text { Randomized Participants } \\
\text { in the Groups }\end{array}$ & 2 & 2 & 2 & 1 & 2 & 2 & 2 & 2 \\
\hline 13. & $\begin{array}{l}\text { Description of Drop-Out } \\
\text { Rate }\end{array}$ & 1 & 2 & 1 & 1 & 2 & 1 & 2 & 2 \\
\hline 14. & $\begin{array}{l}\text { Similarity of Groups at } \\
\text { Baseline for Important } \\
\text { Prognostic Indicators }\end{array}$ & 0 & 2 & 1 & 1 & 1 & 2 & 2 & 2 \\
\hline 15. & Role of Cointerventions & 1 & 1 & 0 & 0 & 0 & 0 & 0 & 0 \\
\hline V. & \multicolumn{9}{|l|}{ RANDOMIZATION } \\
\hline 16. & \begin{tabular}{|l} 
Method of \\
Randomization \\
\end{tabular} & 2 & 1 & 2 & 1 & 2 & 2 & 2 & 0 \\
\hline VI. & \multicolumn{9}{|c|}{ ALLOCATION CONCEALMENT } \\
\hline 17. & $\begin{array}{l}\text { Concealed Treatment } \\
\text { Allocation }\end{array}$ & 2 & 1 & 2 & 0 & 2 & 2 & 2 & 2 \\
\hline VII. & \multicolumn{9}{|l|}{ BLINDING } \\
\hline 18. & Patient Blinding & 1 & 1 & 1 & 0 & 1 & 1 & 1 & 1 \\
\hline 19. & Care Provider Blinding & 0 & 0 & 0 & 0 & 1 & 1 & 0 & 0 \\
\hline 20. & $\begin{array}{l}\text { Outcome Assessor } \\
\text { Blinding }\end{array}$ & 0 & 1 & 1 & 0 & 1 & 1 & 1 & 1 \\
\hline VIII. & \multicolumn{9}{|l|}{ CONFLICTS OF INTEREST } \\
\hline 21. & \begin{tabular}{|l}
$\begin{array}{l}\text { Funding and } \\
\text { Sponsorship }\end{array}$ \\
\end{tabular} & 3 & 0 & 3 & 2 & 2 & 2 & 2 & 2 \\
\hline 22. & Conflicts of Interest & 3 & 3 & 3 & 3 & 3 & 3 & 3 & 3 \\
\hline TOT & & 28 & 28 & 27 & 18 & 37 & 34 & 28 & 28 \\
\hline
\end{tabular}

Source: Manchikanti L, Hirsch JA, Cohen SP, et al. Assessment of methodologic quality of randomized trials of interventional techniques: Development of an interventional pain management specific instrument. Pain Physician 2014; 17:E263-E290 (77). 
318 patients $(68,71,74)$ that provided results for eligible analysis of back pain improvement using VAS and functional status utilizing Oswestry Disability Index (ODI) after 3 months of epidural injection. Analysis showed no statistically significant difference in pain improvement between saline and steroids groups at 3 months follow-up (SMD $0.11[-0.42,0.65], P=0.68$ ) or function (SMD $0.15[0.24,0.55], P=0.45$ ).

\section{Single-Arm Meta-Analysis}

Figure 3 shows the results of single-arm analysis utilizing epidural saline. Three studies $(68,71,74)$ were used to assess back pain score after 3 months of treatment using VAS and ODI in patients who underwent epidural saline injections. As shown in Fig. 3A, the pooled mean difference of pain score from baseline to

Table 5. Results of individual studies based on injected solution $(s)$.

\begin{tabular}{|l|c|c|}
\hline \multicolumn{1}{|c|}{ Study } & $\begin{array}{c}\text { Epidural } \\
\text { Saline }\end{array}$ & $\begin{array}{c}\text { Epidural Saline } \\
\text { with Steroids }\end{array}$ \\
\hline Iversen et al 2011 (71) & 39 & 37 \\
\hline Nandi and Chowdhery 2017 (74) & 47 & 46 \\
\hline Dilke et al 1973 (82) & -- & 50 \\
\hline Carette et al 1997 (68) & 80 & 78 \\
\hline Valat et al 2003 (73) & 42 & 43 \\
\hline Fukusaki et al 1998 (83) & 16 & -- \\
\hline Ghahreman et al 2010 (69) & 37 & -- \\
\hline Karppinen et al 2001 (70) & 80 & -- \\
\hline TOTALS & 341 & 254 \\
\hline
\end{tabular}

3 months of follow-up was decreased by 21.83 points (95\% Cl, -26.137 to $\left.-17.540, P<0.001, \mathrm{I}^{2}=0.00 \%\right)$. As shown in Fig. 3B, the pooled mean difference in ODI score from baseline to 3 months of follow-up was decreased by 9.85 points $(95 \% \mathrm{Cl},-14.10$ to $-5.612, P<$ $0.001, \mathrm{I}^{2}=82.01 \%$ ).

Figure 4 shows changes at 3 months with epidural steroids with single-arm analysis. Three studies $(68,71,74)$ were used to assess pain scores and function after 3 months of treatment using VAS and ODI in patients who underwent epidural steroid injections. The pooled mean difference of pain score from baseline to 3 months of follow-up was decreased by 23.17 points $\left(95 \% \mathrm{Cl},-37.48\right.$ to $\left.-8.8, P<0.005, \mathrm{I}^{2}=89.70 \%\right)$, as shown in Fig. 4A. The pooled mean difference in ODI score from baseline to 3 months of follow-up was decreased by 12.12 points $\left(95 \% \mathrm{Cl},-17.03\right.$ to $-7.21, P<0.001, \mathrm{I}^{2}=$ $74.77 \%$ ), as shown in Fig. 4B.

Overall, there was no significant difference in pain improvement between sodium chloride solution and steroids groups at 3 months follow-up with dual-arm analysis. In contrast, with a single-arm analysis, as shown in Fig. 3A, the pooled mean difference of pain scores from baseline to 3 months follow-up was decreased by 21.83 points. However, ODI scores decreased by 9.85 points (Fig. 3B).

In contrast, assessment of steroids utilizing singlearm analysis, the pain was decreased by 23.17 points (Fig. 4A), however, ODI scores decreased by 12 points (Fig. 4B).

Thus as shown in dual-arm analysis in Fig. 2, there was no difference with changes in pain or function be-

Table 6. Results of epidural injections at 3 months.

\begin{tabular}{|c|c|c|c|c|c|c|c|c|}
\hline \multirow[b]{2}{*}{ Study } & \multicolumn{4}{|c|}{ Sodium Chloride } & \multicolumn{4}{|c|}{ Sodium Chloride with Steroids } \\
\hline & $\begin{array}{c}\text { No. of } \\
\text { Injections }\end{array}$ & $\begin{array}{l}\text { No. of } \\
\text { Patients }\end{array}$ & $\begin{array}{c}\text { Improved } \\
\text { Patients }\end{array}$ & $\begin{array}{l}\text { Improved } \\
\text { Proportion }\end{array}$ & $\begin{array}{l}\text { No. of } \\
\text { Injections }\end{array}$ & $\begin{array}{l}\text { No. of } \\
\text { Patients }\end{array}$ & $\begin{array}{c}\text { Improved } \\
\text { Patients }\end{array}$ & $\begin{array}{l}\text { Improved } \\
\text { Proportion }\end{array}$ \\
\hline Iversen et al 2011 (71) & 2 & 39 & -- & -- & 2 & 37 & -- & -- \\
\hline $\begin{array}{l}\text { Nandi and Chowdhery } \\
2017(74)\end{array}$ & 1 & 46 & 22 & $48 \%$ & 1 & 47 & 28 & $60 \%$ \\
\hline Dilke et al $1973(82)^{*}$ & -- & -- & -- & -- & 2 & 50 & 18 & $36 \% *$ \\
\hline Carette et al 1997 (68) & $1-3$ & 80 & 45 & $56 \%$ & $1-3$ & 78 & 43 & $55 \%$ \\
\hline Valat et al $2003(73) \dagger$ & 3 & 42 & 14 & $34 \%$ & 3 & 43 & 24 & $56 \%$ \\
\hline Fukusaki et al 1998 (83) & $1-3$ & 16 & 1 & $6.3 \%$ & -- & -- & -- & -- \\
\hline $\begin{array}{l}\text { Ghahreman et al } 2010 \\
(69) \dagger\end{array}$ & $1-3$ & 37 & 7 & $19 \%$ & -- & -- & -- & -- \\
\hline Karppinen et al 2001 (70) & 1 & 80 & $>$ better $t$ & han steroid & -- & -- & -- & -- \\
\hline
\end{tabular}

${ }^{*}$ No significant difference with placebo injection of interspinous ligament (22\% vs. 36\%).

$\dagger 3$-month follow-up NA-only $\geq 3$ weeks follow-up available. 
Is Epidural Sodium Chloride a True Placebo?

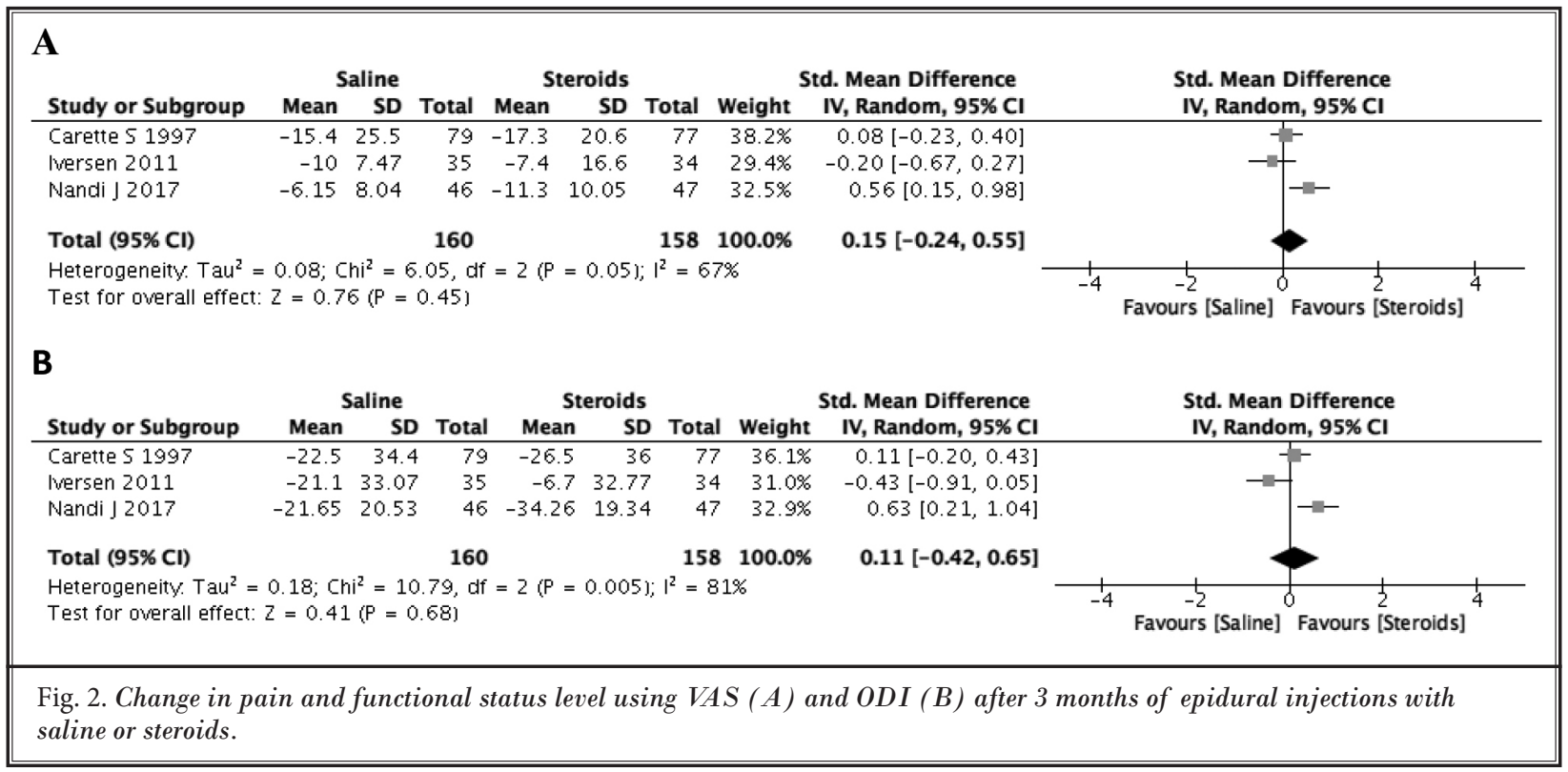

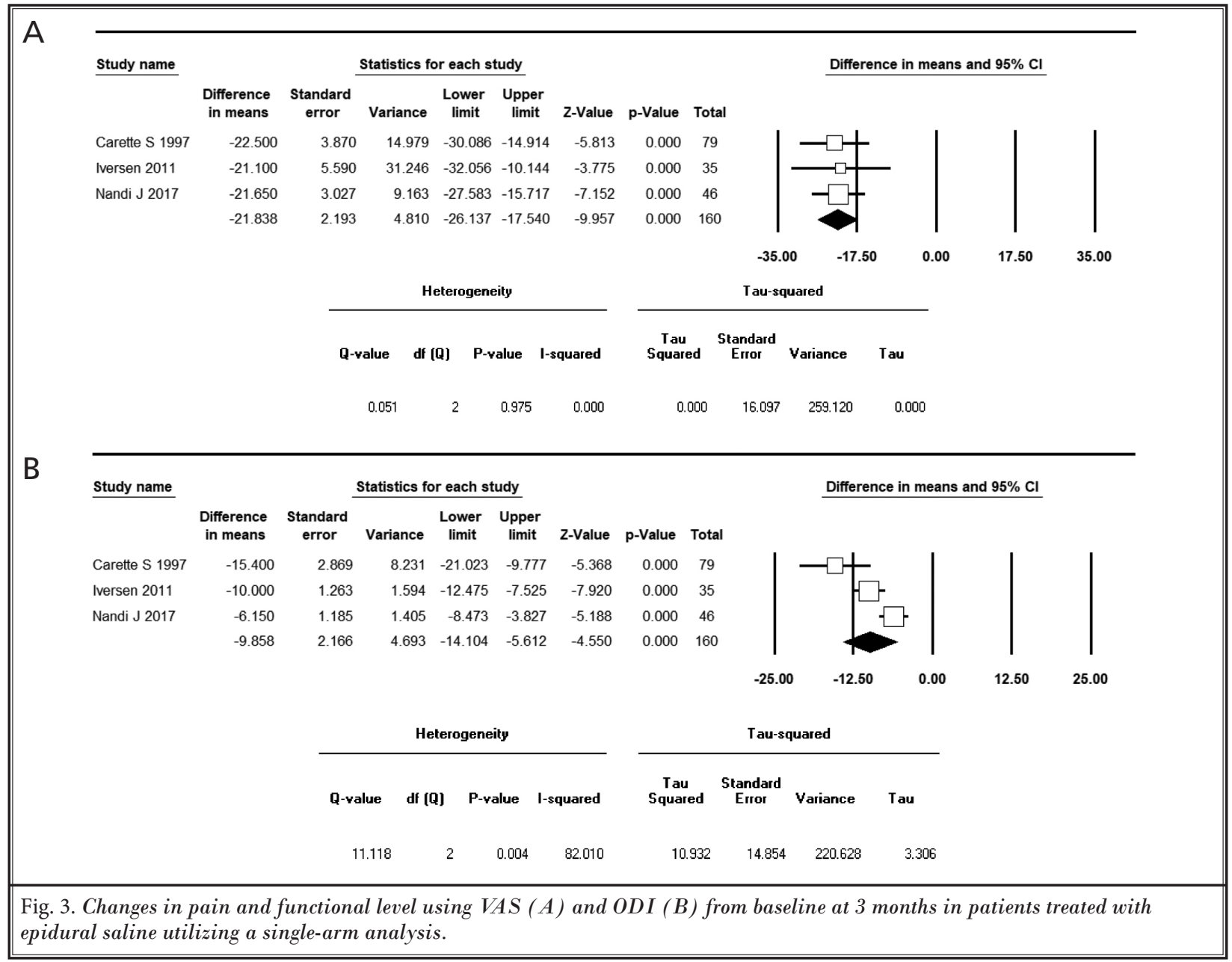




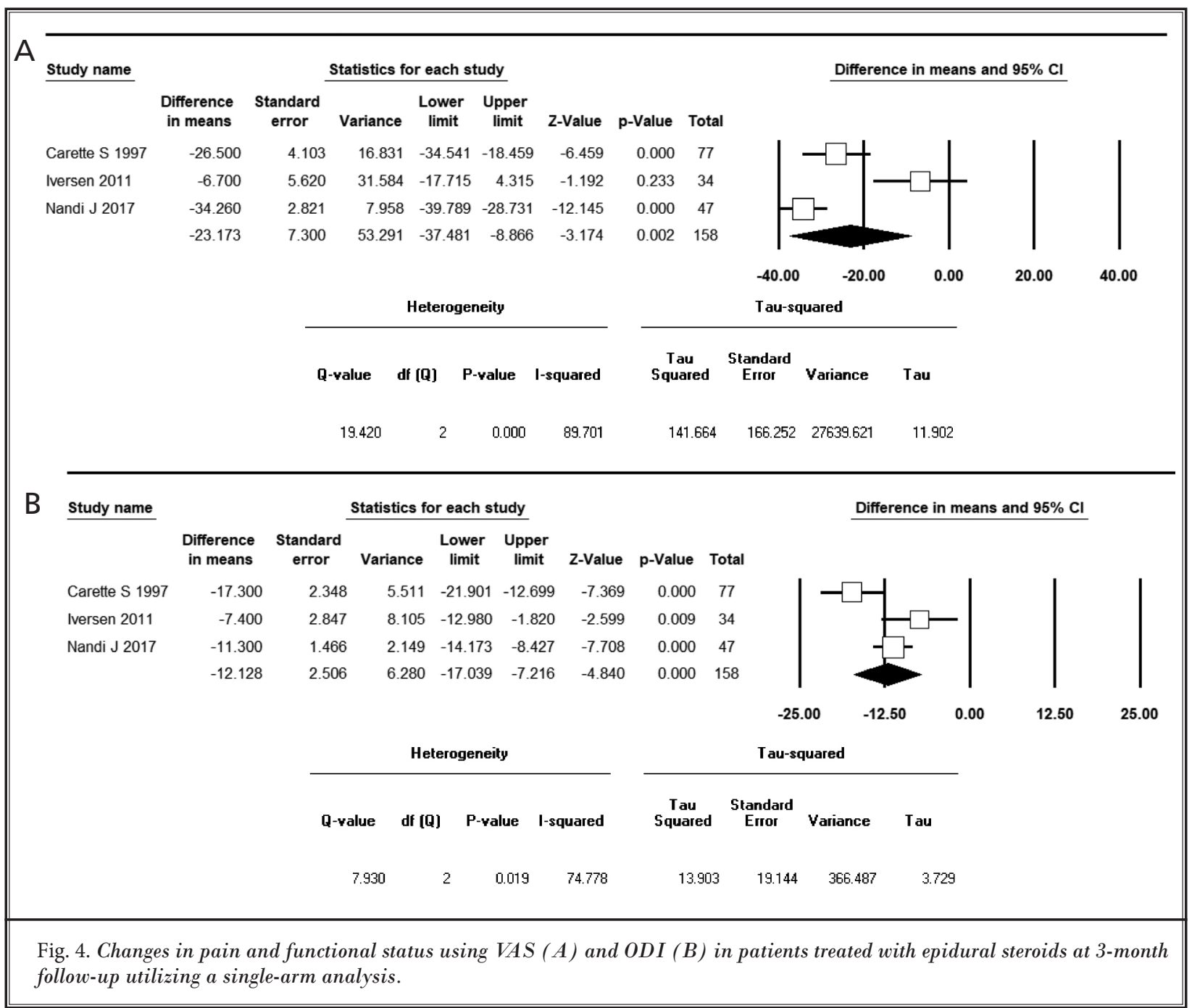

tween sodium chloride solution and steroids in a dualarm analysis.

However, utilizing single-arm analysis, as shown in Figs. $3 B$ and $4 B$, there was a decrease of 9.85 from the baseline ODI scores in the epidural saline group and a 12 -point decrease in the epidural steroids group, which is $10 \%$ to $12 \%$ decrease in functional scores utilizing sodium chloride solution and epidural steroid injections, demonstrating lack of effectiveness of steroids and lack of true placebo effect with epidural sodium chloride solution.

In contrast, as described earlier, the single-arm analysis of effect of epidural saline and steroids showed an approximately $22 \%$ decrease with saline and $23 \%$ decrease with steroids, showing above threshold difference and considered as significant in some studies and indicating lack of true placebo effect of epidurally injected saline and mild effect of epidural steroids, although the results are similar as shown in Figs. 3A and 4A.

\section{Summary of Evidence}

With dual-arm meta-analysis, there was no significant difference between epidural sodium chloride solution and epidural steroids with sodium chloride solution. However, utilizing single-arm analysis both epidural saline and epidural steroids with saline were effective in reducing $20 \%$ of pain; however, only reducing $10 \%$ to $12 \%$ of disability scores.

Based on the qualitative analysis, epidural saline and epidural steroids with saline showed effect beyond placebo and showed level I, or strong evidence, that neither epidural saline, nor epidural steroids with saline are placebo and that both are effective. 


\section{Discussion}

The present systematic review utilizing qualitative analysis and meta-analysis utilizing single-arm analysis showed level II, or moderate evidence, regarding the effectiveness of epidural saline and epidural steroids with saline with pain score reductions greater than $20 \%$ at 3 months, showing lack of true placebo effect with saline and limited effectiveness of steroids. However, this analysis also showed lack of significant difference between epidural saline and epidural steroids with dual-arm analysis, and lack of effectiveness in improving function with single-arm analysis. Further, qualitative analysis showed that epidural saline injections are effective in $40 \%$ of the patients, whereas epidural steroids with saline are effective in $52 \%$ of patients at 3-month follow-up. Thus the evidence is based on qualitative and quantitative analysis with a combination of high-quality and moderate-quality randomized controlled trials. Epidural saline, even in extremely low doses of $1 \mathrm{~mL}$, administered without fluoroscopy was also shown to be effective indicating lack of true placebo effect when injected into the epidural space. Further, the effectiveness of epidural steroids with saline was also demonstrated indicating that steroids are not placebo either. This analysis confirms that epidural saline injection is not a true placebo. A true placebo must be an inert substance injected into an inert structure. Consequently, neither is the epidural space an inert structure, nor is epidurally injected saline an inert solution. This raises numerous questions to experts utilizing all types of epidural injections with saline, but also with local anesthetic injections without corticosteroids; considering them as placebo interventions is based on misconceptions and leads to inaccurate conclusions affecting access to modalities, which are effective.

Steroids, since their application in the epidural space in $1952(19,20)$, have been the subject of controversy in reference to their effectiveness $(21,26)$. Multiple experts $(21,26,59,87)$ have advanced their opinions that epidurally administered sodium chloride solutions, as well as local anesthetic injections, are placebo interventions. Investigators have used the theory that the therapeutic effects in the epidural space are primarily related to the corticosteroids and other drugs are considered as placebo $(21,26)$. The effectiveness of sodium chloride solution or steroids with sodium chloride solution indicates that there are other effects separate from the anti-inflammatory effect described for steroids.
There are multiple additional issues to be considered when assessing the effectiveness of epidurally administered solutions. Local anesthetics have been shown to be equally effective to corticosteroid combined with local anesthetic in an overwhelming majority of patients. Extensive mechanisms have been proposed to describe the effects of epidural local anesthetic, as well as steroids with effects on nociceptive activity (49-58); to some extent that may also be exerted by sodium chloride solution, however, the literature is scant.

This review provides both researchers and interventional practitioners with evidence to consider the injection of an inert substance into an inert structure while performing epidural injection studies, rather than injection of sodium chloride solution, which may or may not be inert in the epidural space, which houses multiple active structures. In addition, all of the literature based on epidural saline and local anesthetics as placebo must either be discarded or reassessed based on the findings of this study with open mindedness and without bias.

To our knowledge, this systematic review is the first of its nature with a single-arm analysis showing the effectiveness of epidurally injected saline in reducing pain and improving function, showing that it is not a true placebo. This also explains multiple discordant conclusions reached in the past, which are based on various challenges, specifically the lack of understanding of placebo control, and consequently leading to the misinterpretation of evidence. Thus this analysis reinforces the major tenant of evidence-based medicine that clinical decisions should be influenced by all relevant high-quality evidence, as opposed to selective studies or selective analysis, as has been seen in many of the reports.

The results of this study, although in agreement with multiple systematic reviews $(12,15,22-25,27-33)$ performed in the past showing positive results of epidural injections, are in conflict with other assessments $(21,26)$. In recent years, multiple systematic reviews have been performed in interventional pain management, which have been described as appropriate with positive results, not only applying principles of placebo control and active control trials, and conventional meta-analysis and single-arm meta-analysis $(10,12,18,22-$ 25,28-33,80,87-96). Further, interventional techniques have been recommended by the authors and multiple agencies to utilize as a deterrent to the opioid epidemic $(97,98)$. 


\section{Conclusions}

This systematic review included high-quality methodological assessment, conventional dual-arm and single-arm meta-analysis. The results clearly showed that epidurally administered sodium chloride solution and sodium chloride solution with steroids may be effective in managing low back and lower extremity pain. Further, there was no significant difference between epidural sodium chloride solution and epidural steroids with sodium chloride solution with conventional dualarm meta-analysis. A single-arm meta-analysis showed equal effectiveness in reducing pain of $20 \%$, whereas disability scores by $10 \%$ to $12 \%$, while both of the solutions were only weakly effective. This meta-analysis proves that epidurally administered sodium chloride solution is not a true placebo.

\section{Acknowledgments}

The authors thank Bert Fellows, MA, Director Emeritus of Psychological Services, Pain Management Centers of America, for manuscript review, and Tonie M. Hatton and Diane E. Neihoff, transcriptionists, for their assistance in preparation of this manuscript. We would like to thank the editorial board of Pain Physician for review and criticism in improving the manuscript.

\section{Author Contributions}

The study was designed by LM, NNK, and JH. Statistical analysis was performed by NNK. All authors contributed to preparation to the manuscript, reviewed, and approved the content with final version.

\section{REFERENCES}

1. Dieleman JL, Cao J, Chapin A, et al. US health care spending by payer and health condition, 1996-2016. JAMA 2020; 323:863-884.

2. U.S. Burden of Disease Collaborators. The state of US health, 1990-2010: Burden of diseases, injuries, and risk factors. JAMA 2013; 310:591-608.

3. Manchikanti L, Sanapati MR, Pampati V, Boswell MV, Kaye AD, Hirsch JA. Update on reversal and decline of growth of utilization of interventional techniques in managing chronic pain in the Medicare population from 2000 to 2018. Pain Physician 2019; 22:521-536.

4. Manchikanti L, Sanapati MR, Soin A, et al. An updated analysis of utilization of epidural procedures in managing chronic pain in the Medicare population from 2000 to 2018. Pain Physician 2020; 23:111-126.

5. Manchikanti L, Soin A, Mann DP, Bakshi S, Pampai V, Hirsch JA. Comparative analysis of utilization of epidural procedures in managing chronic pain in the Medicare population: Pre and post Affordable Care Act. Spine (Phila Pa 1976) 2019; 44:220-232.

6. Manchikanti L, Sanapati MR, Pampati $V$, et al. Update of utilization patterns of facet joint interventions in managing spinal pain from 2000 to 2018 in the US fee-for-service Medicare population. Pain Physician 2020; 23:E133-E149.

7. Manchikanti L, Manchikanti MV, Vanaparthy R, Kosanovic R, Pampati V.
Utilization patterns of sacroiliac joint injections from 2000 to 2018 in feefor-service Medicare population. Pain Physician 2020; 23:439-450.

8. Manchikanti L, Kosanovic R, Pampati $V$, Kaye AD. Declining utilization patterns of percutaneous adhesiolysis procedures in the United States feefor-service (FFS) Medicare population. Pain Physician 2021; in press.

9. Manchikanti L, Kaye A, Soin A, et al. Comprehensive evidence-based guidelines for facet joint interventions in the management of chronic spinal pain: American Society of Interventional Pain Physicians (ASIPP) Guidelines. Pain Physician 2020; 23:S1-S127.

10. Navani A, Manchikanti L, Albers SL, et al. Responsible, safe, and effective use of biologics in the management of low back pain: American Society of Interventional Pain Physicians (ASIPP) guidelines. Pain Physician 2019; 22:S1-S74.

11. Manchikanti L, Vanaparthy R, Atluri S, Sachdeva H, Kaye AD, Hirsch JA. Concurrent public health emergencies in the US: COVID-19 and the opioid epidemic with hampered access to chronic pain management: A review. Pain Ther 2020; in press.

12. Manchikanti L, Knezevic NN, Boswell MV, Kaye AD, Hirsch JA. Epidural injections for lumbar radiculopathy and spinal stenosis: A comparative systematic review and meta-analysis.
Pain Physician 2016; 19:E365-E410.

13. Sicard JA. Les injections medicamenteuse extraduraqles per voie saracoccygiene. Comptes Renues des Senances de la Societe de Biolgie et de ses Filliales 1901; 53:396-398.

14. Ter Meulen BC, Weinstein H, Ostelo $\mathrm{R}$, Koehler PJ. The epidural treatment of sciatica: Its origin and evolution. Eur Neurol 2016; 75:58-64.

15. Shanthanna $H$, Busse J, Wang L, et al. Addition of corticosteroids to local anaesthetics for chronic non-cancer pain injections: A systematic review and meta-analysis of randomised controlled trials. Br J Anaesth 2020; 125:779-801.

16. Evans W. Intrasacral epidural injection in the treatment of sciatica. The Lancet 1930; 216:1225-1229.

17. Coomes EN. A comparison between epidural anaesthesia and bed rest in sciatica. Br Med J 1961; 1:20-24.

18. Manchikanti L, Nampiaparampil DE, Manchikanti KN, et al. Comparison of the efficacy of saline, local anesthetics, and steroids in epidural and facet joint injections for the management of spinal pain: A systematic review of randomized controlled trials. Surg Neurol Int 2015; 6:S194-S235.

19. Robecchi A, Capra R. Hydrocortisone (compound F); first clinical experiments in the field of rheumatology. Minerva Med 1952; 98:1259-1263.

20. Lievre JA, Bloch-Mechel H, Pean G. 
L'hydrocortisone en injection locale. Rev Rhum 1953; 20:310-311.

21. Chou R, Hashimoto R, Friedly J, et al. Epidural corticosteroid injections for radiculopathy and spinal stenosis: $A$ systematic review and meta-analysis. Ann Intern Med 2015; 163:373-381.

22. Lewis R, Williams $\mathrm{N}$, Matar $\mathrm{HE}$, et al. The clinical effectiveness and cost effectiveness of management strategies for sciatica: Systematic review and economic model. Health Technol Assess 2011; 15:1-578.

23. Lewis RA, Williams $\mathrm{NH}$, Sutton AJ, et al. Comparative clinical effectiveness of management strategies for sciatica: Systematic review and network metaanalyses. Spine ] 2015; 15:1461-1477.

24. Guo JR, Jin XJ, Shen HC, et al. A comparison of the efficacy and tolerability of the treatments for sciatica: A network meta-analysis. Ann Pharmacother 2017; 51:1041-1052.

25. Lee JH, Kim DH, Kim DH, et al. Comparison of clinical efficacy of epidural injection with or without steroid in lumbosacral disc herniation: A systematic review and meta-analysis. Pain Physician 2018; 21:449-468.

26. Pinto RZ, Maher CG, Ferreira ML, et al. Epidural corticosteroid injections in the management of sciatica: A systematic review and meta-analysis. Ann Intern Med 2012; 157:865-877.

27. Bicket M, Gupta A, Brown CH, Cohen SP. Epidural injections for spinal pain: A systematic review and meta-analysis evaluating the "control" injections in randomized controlled trials. Anesthesiology 2013; 119:907-931.

28. Knezevic N, Manchikanti L, Urits I, et al. Lack of superiority of epidural injections with lidocaine with steroids compared to without steroids in spinal pain: A systematic review and meta-analysis. Pain Physician 2020; 23:S239-S270.

29. Manchikanti L, Kosanovic R, Vanaparthy $R$, et al. Steroid distancing in interventional pain management during COVID-19 and beyond: Safe, effective and practical approach. Pain Physician 2020; 23:S319-S352.

30. Mesregah MK, Feng W, Huang WH, et al. Clinical effectiveness of interlaminar epidural injections of local anesthetic with or without steroids for managing chronic neck pain: A systematic review and meta-analysis. Pain Physician 2020; 23:335-348.

31. Zhao W, Wang Y, Wu J, et al. Long-term outcomes of epidurals with lidocaine with or without steroids for lumbar disc herniation and spinal stenosis: A meta-analysis. Pain Physician 2020; 23:365-374.

32. Manchikanti L, Knezevic NN, Sanapati SP, Sanapati MR, Kaye AD, Hirsch JA. Is percutaneous adhesiolysis effective in managing chronic low back and lower extremity pain in post-surgery syndrome: A systematic review and meta-analysis. Curr Pain Headache Rep 2020; 24:30.

33. Manchikanti L, Knezevic NN, Sanapati MR, Boswell MV, Kaye AD, Hirsch JA. Effectiveness of percutaneous adhesiolysis in managing chronic central lumbar spinal stenosis: A systematic review and meta-analysis. Pain Physician 2019; 22:E523-E550.

34. Eden J, Levit L, Berg A, Morton S (eds); Committee on Standards for Systematic Reviews of Comparative Effectiveness Research; Institute of Medicine. Finding What Works in Health Care. Standards for Systematic Reviews. Washington, DC, The National Academies Press, 2011.

35. Flier JS. Conflict of interest among medical school faculty: Achieving a coherent and objective approach. JAMA 2017; 317:1731-1732.

36. Cappola AR, FitzGerald GA. Confluence, not conflict of interest: Name change necessary. JAMA 2015; 314:1791-1792.

37. Greenhalgh T, Howick J, Maskrey N; Evidence Based Medicine Renaissance Group. Evidence based medicine: a movement in crisis? BMJ 2014; 348:g3725.

38. Rysavy M. Evidence-based medicine: A science of uncertainty and an art of probability. AMA J Ethics 2013; 15:4-8.

39. Masic I, Miokovic M, Muhamedagic B. Evidence based medicine: New approaches and challenges. Acta Inform Med 2008; 16:219-225.

40. Hench PS, Kendall EC, et al. The effect of a hormone of the adrenal cortex (17-hydroxy-11-dehydrocorticosterone; compound E) and of pituitary adrenocorticotropic hormone on rheumatoid arthritis. Proc Staff Meet Mayo Clin 1949; 24:181-197.

41. Wong SH, Wong CS, Li TT. Steroids in regional analgesia. Expert Opin Pharmacother 2010; 11:2839-2848.

42. Stevens T, Costanzo A, Lopez R, Kapural L, Parsi MA, Vargo JJ. Adding triamcinolone to endoscopic ultrasound-guided celiac plexus blockade does not reduce pain in patients with chronic pancreatitis. Clin Gastroenterol Hepatol 2012; 10:186-191.

43. Uthman I, Raynauld JP, Haraoui B. Intra-articular therapy in osteoarthritis. Postgrad Med J 2003; 79:449-453.

44. Rijsdijk $M$, van Wijck AJ, Kalkman C), Yaksh TL. The effects of glucocorticoids on neuropathic pain: A review with emphasis on intrathecal methylprednisolone acetate delivery. Anesth Analg 2014; 118:1097-1112.

45. Bogduk N. Epidural steroids. Spine (Phila Pa 1976) 1995; 20:845-848.

46. National Health and Medical Research Council. Epidural use of steroids in the management of back pain. Canberra: Commonwealth of Australia, National Health and Medical Research Council, 1994.

47. Devor M, Govrin-Lippmann R, Raber P. Corticosteroids suppress ectopic neural discharge originating in experimental neuromas. Pain 1985; 22:127-137.

48. Johannson A, Hao J, Sjolund B. Local corticosteroid application blocks transmission in normal nociceptive C-fibres. Acta Anaesthesiol Scand 1990; 34:335-338.

49. Mao J, Chen LL. Systemic lidocaine for neuropathic pain relief. Pain 2000; 87:7-17.

50. Ferrante FM, Paggioli J, Cherukuri S, Arthru GR. The analgesic response to intravenous lidocaine in the treatment of neuropathic pain. Anesth Analg 1996; 82:91-97.

51. Lavoie PA, Khazen T, Filion PR. Mechanisms of the inhibition of fast axonal transport by local anesthetics. Neuropharmacology 1989; 28:175-181.

52. Bisby MA. Inhibition of axonal transport in nerves chronically treated with local anesthetics. Exp Neurol 1975; 47:481-489.

53. Kawakami M, Weinstein JN, Chatani K, Spratt KF, Meller ST, Gebhart GF. Experimental lumbar radiculopathy. Behavioral and histologic changes in a model of radicular pain after spinal nerve root irritation with chromic gut ligatures in the rat. Spine (Phila Pa 1976) 1994; 19:1795-1802.

54. Tachihara H, Sekiguchi M, Kikuchi S, Konno S. Do corticosteroids produce additional benefit in nerve root infiltration for lumbar disc herniation. Spine (Phila Pa 1976) 2008; 33:743-747.

55. Pasqualucci A. Experimental and 
clinical studies about the preemptive analgesia with local anesthetics. Possible reasons of the failure. Minerva Anestesiol 1998; 64:445-457.

56. Arner S, Lindblom U, Meyerson BA, Molander C. Prolonged relief of neuralgia after regional anesthetic block. A call for further experimental and systematic clinical studies. Pain 1990; 43:287-297.

57. Sato C, Sakai A, Ikeda Y, Suzuki H, Sakamoto A. The prolonged analgesic effect of epidural ropivacaine in a rat model of neuropathic pain. Anesth Analg 2008; 106:313-320.

58. Hamaya C, Barr T, Strichartz GR. Multiple inhibitory mechanisms of lidocaine on bradykinin receptor activity in model sensory neurons. Reg Anesth Pain Med 2018; 43:605-612.

59. Manchikanti L, Boswell MV, Kaye AD, Helm li S, Hirsch JA. Therapeutic role of placebo: Evolution of a new paradigm in understanding research and clinical practice. Pain Physician 2017; 20:363-386.

6o. Tsui BC, Wagner A, Funicane B. Electrophysiologic effect of injectates on peripheral nerve stimulation. Reg Anesth Pain Med 2004; 29:189-193.

61. Ercole A. The effect of injectate conductivity on the electric field with the nerve stimulator needle: A computer simulation. Anesth Analg 2008; 107:1427-1432.

62. Tsui BC, Kropelin B. The electrophysiological effect of dextrose $5 \%$ in water on single-shot peripheral nerve stimulation. Anesth Analg 2005; 100:1837-1839.

63. Tsui BC, Kropelin B, Ganapathy S, Finucane B. Dextrose $5 \%$ in water: Fluid medium for maintaining electrical stimulation of peripheral nerves during stimulating catheter placement. Acta Anaesthesiol Scand 2005; 49:1562-1565.

64. Maniquis-Smigel L, Reeves KD, Rosen $\mathrm{HJ}$, et al. Analgesic effect and potential cumulative benefit from caudal epidural $\mathrm{d}_{5} \mathrm{w}$ in consecutive participants with chronic low-back and buttock/leg pain. J Altern Complement Med 2018; 24:1189-1196.

65. Maniquis-Smigel L, Reeves KD, Jeffrey Rosen $\mathrm{H}$, et al. Short term analgesic effects of $5 \%$ dextrose epidural injections for chronic low back pain: A randomized controlled trial. Anesth Pain Med 2016; 7:e42550.

66. Koh WU, Choi SS, Park WY, et al.
Transforaminal hypertonic saline for the treatment of lumbar lateral canal stenosis: A double-blinded, randomized, active-control trial. Pain Physician 2013; 16:197-211.

67. Joo EY, Koh WU, Choi SS, et al. Efficacy of adjuvant 10\% hypertonic saline in transforaminal epidural steroid injection: A retrospective analysis. Pain Physician 2017; 20:E107-E114.

68. Carette S, Leclaire R, Marcoux S, et al. Epidural corticosteroid injections for sciatica due to herniated nucleus pulposus. N Engl J Med 1997; 336:1634-1640.

69. Ghahreman A, Ferch R, Bogduk N. The efficacy of transforaminal injection of steroids for the treatment of lumbar radicular pain. Pain Med 2010; 11:1149-1168.

70. Karppinen J, Malmivaara A, Kurunlahti $M$, et al. Periradicular infiltration for sciatica: A randomized controlled trial. Spine (Phila Pa 1976) 2001; 26:1059-1067.

71. Iversen T, Solberg TK, Romner B, et al. Effect of caudal epidural steroid or saline injection in chronic lumbar radiculopathy: Multicentre, blinded, randomised controlled trial. BMJ 2011; $343: \mathrm{d}_{5278 .}$

72. Cohen SP, White RL, Kurihara C, et al. Epidural steroids, etanercept, or saline in subacute sciatica: A multicenter, randomized trial. Ann Intern Med 2012; 156:551-559.

73. Valat JP, Giraudeau B, Rozenberg S, et al. Epidural corticosteroid injections for sciatica: A randomised, double blind, controlled clinical trial. Ann Rheum Dis 2003; 62:639-643.

74. Nandi J, Chowdhery A. A randomized controlled clinical trial to determine the effectiveness of caudal epidural steroid injection in lumbosacral sciatica. J Clin Diagn Res 2017; 11:RCo4-RCo8.

75. Preferred Reporting Items for Systematic Reviews and Meta-Analyses (PRISMA). Available at: h t t p : // prisma-statement.org/. Accessed November 30, 2020.

76. Furlan AD, Malmivaara A, Chou R, et al; Editorial Board of the Cochrane Back, Neck Group. 2015 Updated method guideline for systematic reviews in the Cochrane Back and Neck Group. Spine (Phila Pa 1976) 2015; 40:1660-1673.

77. Manchikanti L, Hirsch JA, Cohen SP, et al. Assessment of methodologic quality of randomized trials of interventional techniques: Development of an interventional pain management specific instrument. Pain Physician 2014; 17:E263-E290.

78. Manchikanti L, Falco FJE, Benyamin RM, Kaye AD, Boswell MV, Hirsch JA. A modified approach to grading of evidence. Pain Physician 2014; 17:E319-E325.

79. Wu T, Song HX, Dong Y, Li JH. Cellbased therapies for lumbar discogenic low back pain: Systematic review and single-arm meta-analysis. Spine (Phila Pa 1976) 2018; 43:49-57.

8o. Sanapati J, Manchikanti L, Atluri S, et al. Do regenerative medicine therapies provide long-term relief in chronic low back pain: A systematic review and metaanalysis. Pain Physician 2018; 21:515-540.

81. Revel M, Auleley GR, Alaoui S, et al. Forceful epidural injections for the treatment of lumbosciatic pain with post-operative lumbar spinal fibrosis. Rev Rhum Engl Ed 1996; 63:270-277.

82. Dilke TF, Burry HC, Grahame R. Extradural corticosteroid injection in the management of lumbar nerve root compression. Br Med J 1973; 2:635-637.

83. Fukusaki M, Kobayashi I, Hara T, Sumikawa K. Symptoms of spinal stenosis do not improve after epidural steroid injection. Clin J Pain 1998; 14:148-151.

84. Cohen SP, Hanling S, Bicket MC, et al. Epidural steroid injections compared with gabapentin for lumbosacral radicular pain: Multicenter randomized double blind comparative efficacy study. BM] 2015; 350:h1748.

85. Cohen SP, Hayek S, Semenov Y, et al. Epidural steroid injections, conservative treatment, or combination treatment for cervical radicular pain: A multicenter, randomized, comparativeeffectiveness study. Anesthesiology 2014; 121:1045-1055.

86. Kraemer J, Ludwig J, Bickert U, Owczarek V, Traupe M. Lumbar epidural perineural injection: A new technique. Eur Spine J 1997; 6:357-361.

87. Beall DP, Tutton SM, Murphy K, Olan W, Warner CB, Test JB. Analysis of reporting bias in vertebral augmentation. Pain Physician 2017; 20:E1081-E1090.

88. Kaye AD, Manchikanti L, Novitch $M B$, et al. Responsible, safe, and effective use of antithrombotics and anticoagulants in patients undergoing interventional techniques: American Society of Interventional Pain Physicians (ASIPP) guidelines. Pain 
Physician 2019; 22:S75-S128.

89. Zhiyong C, Yun T, Hui F, Zhongwei $Y$, Zhaorui L. Unilateral versus bilateral balloon kyphoplasty for osteoporotic vertebral compression fractures: A systematic review of overlapping metaanalyses. Pain Physician 2019; 22:15-28.

90. Tran ZV, Ivashchenko A, Brooks L. Sacroiliac joint fusion methodologyminimally invasive compared to screwtype surgeries: A systematic review and meta-analysis. Pain Physician 2019; 22:29-40.

91. Sanger $N$, Bhatt $M$, Singhal $N$, et al. Adverse outcomes associated with prescription opioids for acute low back pain: A systematic review and metaanalysis. Pain Physician 2019; 22:119-138.

92. Coulter ID, Crawford C, Vernon H, et al. Manipulation and mobilization for treating chronic nonspecific neck pain: A systematic review and meta-analysis for an appropriateness panel. Pain Physician 2019; 22:E55-E70.

93. Lin CS, Lin YC, Lao HC, Chen CC. Interventional treatments for postherpetic neuralgia: A systematic review. Pain Physician 2019; 22:209-228.

94. Moride Y, Lemieux-Uresandi D, Castillon $\mathrm{G}$, et al. A systematic review of interventions and programs targeting appropriate prescribing of opioids. Pain Physician 2019; 22:229-240.

95. Zhang $\mathrm{X}$, Liang $\mathrm{Y}$, Zhang $\mathrm{N}$, et al. The relevance of the OPRM $118 \mathrm{~A}>\mathrm{G}$ genetic variant for opioid requirement in pain treatment: A meta-analysis. Pain Physician 2019; 22:331-340.
96. Li Z, Chen L, Li B, Wei J. Efficacy and safety of surgical interventions for treating multilevel cervical spondylotic myelopathy via anterior approach: A network meta-analysis. Pain Physician 2019; 22:E275-E286.

97. U.S. Department of Health and Human Services. Pain Management Best Practices Inter-Agency Task Force. Final Report on Pain Management Best Practices: Updates, Gaps, Inconsistencies, and Recommendations. May 9, 2019. Available at: www.hhs.gov/ ash/advisory-committees/pain/reports/ index.html. Accessed November 30, 2020.

98. Manchikanti L, Singh V, Kaye AD, Hirsch JA. Lessons for better pain management in the future: Learning from the past. Pain Ther 2020; 9:373-391. 
